the "Ten Commandments" systematic approach had been followed, ${ }^{5}$ and the lumbar spine radiographs had been viewed systematically (Adequacy-Alignment-Bones-Cartilages and joints-Soft tissues), the diagnosis of an aortic aneurysm may have been made within two days of the onset of symptoms. It is recommended that all emergency radiographs are reviewed and a report returned to the $A \& E$ department within three working days. The two week delay in this case was clearly unacceptable.
1 Maddison PJ, Isenberg DA, Woo P, Glass DN. Oxford textbook of rheumatology. Oxford: Oxford University Press, 1993.

2 Williams PL, ed. Grays anatomy, 38th ed. London: Churchill Livingstone, 1995.

3 Szilagyi DE, Smith RF, Macksood AJ, Whitcomb JG. Expanding and ruptured aortic aneurysm: problems of diagnosis and treatment. Arch Surg 1961;83:395-408.

4 Ashleigh RG, Marcuson RW. False aortic aneurysm presenting as sciatic nerve root pain. Eur J Vasc Surg 1993; 7:214-6.

5 Touquet R, Driscoll P, Nicholson D. Ten commandments of emergency radiology. In: Nicholson $D$, Driscoll $P$, eds. The $\mathrm{ABC}$ of emergency radiology. London: BMJ Publishing Group, 1995.

\title{
Neck pain as a presenting symptom in malignant hypertension
}

\author{
Joanna Stockwell, Grizelda George
}

\begin{abstract}
Neck pain, unrelated to trauma, is relatively common and is usually presumed to be musculoskeletal in origin. A patient presented with an unusual and serious cause of neck pain-malignant hypertension. The mechanism of the neck pain may be incipient tonsillar herniation of the cerebellum caused by raised intracranial pressure.
\end{abstract}

( Accid Emerg Med 1997;14:51-52)

Keywords: neck pain; malignant hypertension

We describe a patient who presented to the accident and emergency (A\&E) department complaining of neck pain as a presenting symptom in malignant hypertension.

Malignant hypertension is characterised by very high blood pressure with papilloedema and retinopathy. There is associated organ failure, most commonly of the kidneys and heart. The most frequent presenting symptom is headache, often accompanied by other symptoms of hypertensive encephalopathy such as vomiting, blurred vision, and fits. There may also be symptoms of renal and cardiac insufficiency, for example, lethargy and shortness of breath. Neck pain has not previously been described as a presenting symptom in malignant hypertension.

\section{Case report}

Horton General Hospital NHS Trust, Banbury, Oxfordshire J Stockwell

G George

Correspondence to: Miss Grizelda George FRCS, FFAEM, Consultant in Accident \& Emergency, Horton General Hospital NHS Trust, Oxford Road, Banbury, Oxon OX16 9AL.
A 33 year old female patient presented to the A\&E department complaining of neck pain on waking for the previous 10 days. She had seen her general practitioner (GP) who had diagnosed musculoskeletal neck pain and had prescribed ibuprofen and a soft collar. On further blurred vision. She had, in fact, felt unwell for one month, with loss of appetite, nausea and vomiting, lethargy, weakness, intermittent sharp chest pains, and shortness of breath. She had no significant past medical history. She used an oral contraceptive and smoked 15 questioning, she complained of headache and cigarettes a day. She was a single mother with four children.

On examination, she looked well. However, she was significantly hypertensive with a blood pressure $250 / 120 \mathrm{~mm} \mathrm{Hg}$. The apex beat was not displaced. She had gross papilloedema. She was mildly photophobic. She was tender over the neck but there was no neck stiffness. There were no other abnormal signs. Preliminary investigation showed advanced renal impairment with a plasma creatinine of 543 $\mu \mathrm{mol} / \mathrm{litre}$. Her urine contained blood and protein. ECG and chest $x$ ray were normal. A diagnosis of malignant hypertension was made and she underwent renal biopsy which showed markedly sclerosed glomeruli. She is currently being treated for a rapidly progressive glomerulonephritis.

\section{Discussion}

Malignant hypertension is a potentially life threatening emergency which usually presents with headache. However, in the case described here it presented with neck pain which mimicked non-traumatic, musculoskeletal neck pain.

Although neck pain has not previously been described in malignant hypertension, magnetic resonance imaging (MRI) and single photon emission computerised tomography (SPECT) suggest reasons for it. Hypertensive encephalopathy produces cerebral oedema with regional hyperperfusion of the occipital cortex and cerebellum. ${ }^{1}$ The cerebral oedema causes raised intracranial pressure-hence the papilloedema, headache (worse on waking), and the vomiting which are so common in malignant hypertension. Hyperperfusion of the occipital cortex may contribute to the visual symptoms, as may the papilloedema. Cerebellar hyperperfusion, together with raised intracranial pressure, would be expected to cause a degree of tonsillar herniation through the foramen magnum. Neck pain has been described as a presenting symptom in tonsillar herniation. ${ }^{2}$ It therefore seems reasonable to attribute the 


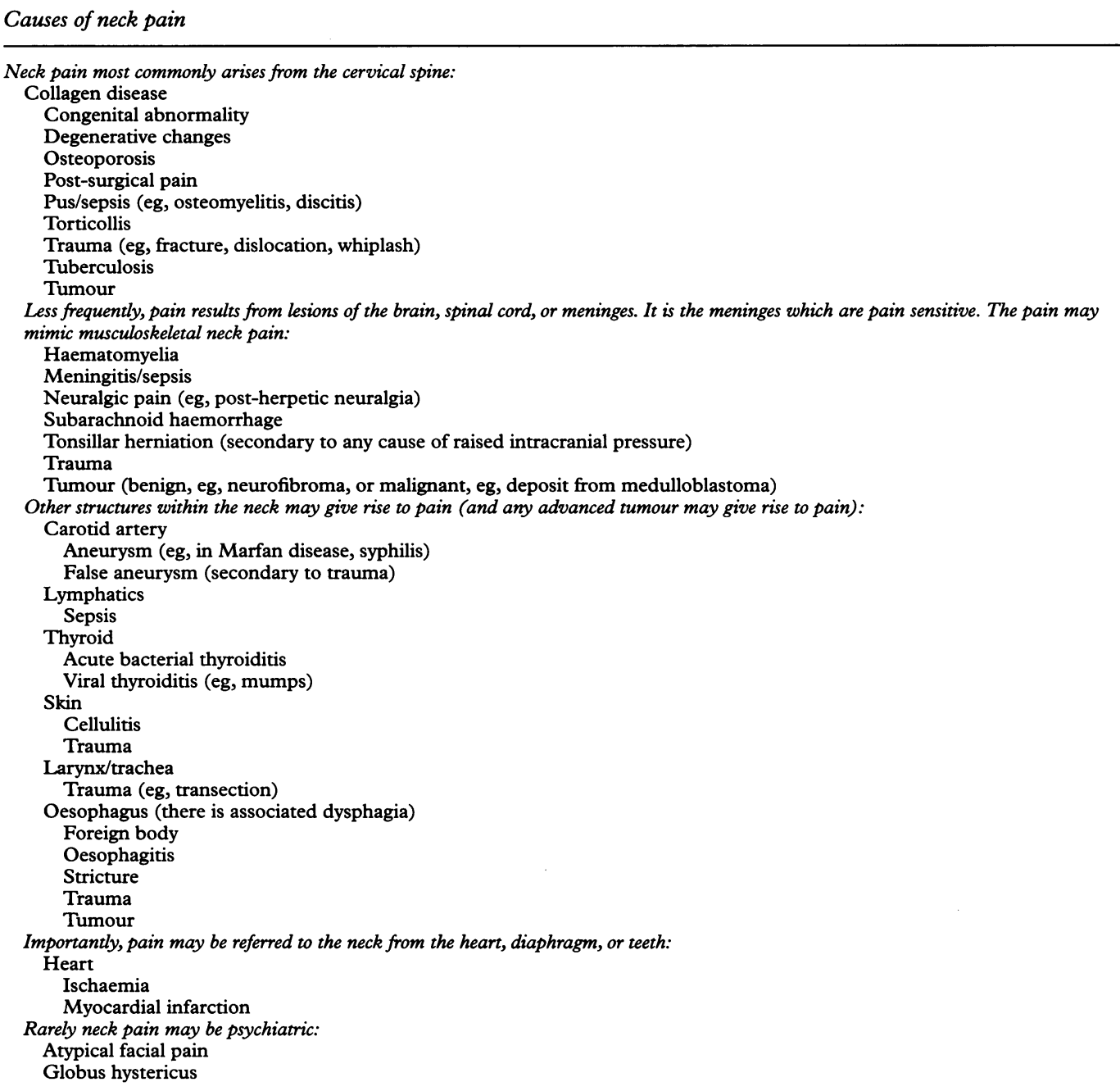

neck pain in our patient, which was worse on waking, to this cause.

Other serious causes for neck pain, which may mimic musculoskeletal neck pain, include subarachnoid haemorrhage, which is characterised by sudden, severe pain. This arises either because the haemorrhage is spinal in origin or because blood from a cerebral bleed tracks into the spinal subarachnoid space. Blood may even gravitate into the lumbar culde-sac, producing back pain and sciatica at presentation. ${ }^{3}$ It is therefore important to consider the various causes of neck pain when assessing patients so that serious, uncommon emergencies are not missed (table). The history may be acute, as in subarachnoid haemorrhage or myocardial infarction. How- ever, in the present case the patient had a 10 day history and had already seen her GP. We therefore recommend that history taking includes a brief inquiry about the timing and onset of symptoms, associated headache, and general wellbeing.

We thank Dr A Molyneux, consultant neuroradiologist, for suggesting the mechanism for the neck pain in our patient and D $\mathrm{K}$ Choji, consultant radiologist, for his review of the literature. We also thank Mr S Watt-Smith, consultant facio-maxillary surgeon, for his help in preparing the table.

1 Schwartz RB, Jones KM, Kalina P, Bajakian RL, Mantello $M, G a r a d a$ B, et al. Hypertensive encephalopathy: finding on CT, MR imaging and SPECT imaging in 14 cases. Am J Radiol 1992;159:379-83.

2 Dure LS, Percy AK, Cheek WR, Laurent JP. Chiari type I malformation in children. J Pediatr 1989;115:573-6.

3 Jennett B, Galbraith S. An introduction to neurosurgery. London: William Heinemann, 1983.
Department of

Emergency Medicine,

Hope Hospital,

Salford, United

Kingdom

R Birkinshaw

J O'Donnell

I Sammy

Correspondence to: Mr Ian Sammy, Department of Emergency Medicine,

Hope Hospital, Stott Lane, Salford, M6 8HD.

Accepted for publication 18 September 1996

\section{Necrotising fasciitis as a complication of steroid injection}

\author{
R Birkinshaw, J O’Donnell, I Sammy
}

\author{
Abstract \\ Necrotising fasciitis is described as a \\ complication of steroid injection of a
}

painful shoulder in a previously well 